\title{
Application of Mathematical Model to Assess Sediment Movement Pattern along Nearshore Coastal Water
}

\author{
Sumaya Hossain \\ Department of Water Resource Engineering, Bangladesh University of Engineering \& Technology, Dhaka 1000, Bangladesh
}

\begin{abstract}
Movement of sediment load and its pattern of transportation along nearshore coastal water is a very important phenomenon to be assessed for different sector of coastal Engineering. To develop and understand the physical processes responsible for shaping the ongoing evolution of the coast and to develop the management strategies to deal the impact of human activities on the coastal zone and as well as for adapting to the hazards associated with the people living on the coast, knowledge of the mechanism, processes and the pattern of sediment movement in the nearshore zone is of utmost importance. Nearshore zone is a very active area, where a series of dynamic processes occur in response to changing wave climates and sediment budgets. Nowadays mathematical modeling is an attractive alternative and becoming a very viable approach to study the sediment movement pattern with the advanced computational facilities and improved understanding on wave mechanics and sediment transport processes. It is very effective, reliable and also comfortable to study the pattern of sediment transportation including yield, distribution and management of sediment with the help of mathematical model. Validity of forecast in sediment transport depends on both mathematical modeling technique and boundary conditions.
\end{abstract}

Key words: Sediment movement, nearshore zone, mathematical model, boundary condition.

\section{Introduction}

Coastal zones are continually changing because of dynamic interaction between the ocean and land. Tides, waves and winds are responsible for depositing sediment on a continuous basis along such zones. It results in the formation of characteristic coastal landforms such as beaches, barrier and capes [1]. The shape of the coastal zone is quite unstable due to the erosion and accretion [2]. In system with boundaries that are subject to deposition or scour, it is necessary to model the movement of the sediment particles with the flow to study different phenomena of the coast. Although sediment transport modeling is a complex topic and is subject to much uncertainty, mathematical modeling is comparatively effective and reliable in studying the process and pattern of sediment movement along the nearshore coastal water. The coastal sediment transport is one of the

Corresponding author: Sumaya Hossain, M.Sc. in water resource engineering, research fields: sediment transport engineering, coastal engineering and estuarine hydraulics. important processes that controls the beach morphology, and determines in large part whether shores erode, accrete, or remain stable. Huge amounts of sediment are being used for flood protection, beach nourishment and habitat and wetland protection. Sediment transport is one of the main tools in coastal zone management and coastal engineering design practice. Assessment of the sediment movement pattern along the nearshore coastal water with the help of mathematical model is a very effective and easy solution for all these contexts.

\section{Sediment Transport Mechanism in Nearshore Zone}

The nearshore zone extends from the low tide line out to a water depth where wave motion ceases to affect the sea floor. It acts as a link between the coast and the inner continental shelf and materials can move in both direction across it. It is a very active area, where a series of dynamic processes occur in response to changing wave climates and sediment budgets [3]. 
These processes involve the action of waves, breaking of waves, currents, turbulence, wave-current interaction and other dynamic processes. Here the sediment transport is driven by the combined motions of water waves and currents. As wave travels from the deep water of the nearshore zone towards the shoreline, they are increasingly affected by the bed friction and the process of wave shoaling and eventually the wave breaks.

In addition to the orbital motion associated with the waves, wave breaking generates strong unidirectional currents within the surf zone close to the beach and this is responsible for both in cross shore and long shore sediment transport [4]. Wind, tidal and wave-induced currents act in the nearshore zone shaping morphology and determining sediment textures by interaction and performing jointly a flexible dynamical equilibrium. During large wave events, the sediment gets transported off the beach face an offshore deposition generating a sandbar. Once the significant wave event has diminished, the sediment then gets slowly transported back onshore
[5]. Different combinations of wave and current interaction causes complicated patterns of grain transport that are not always reflected by the bedform configurations. In these areas, the use of bedform for current and sediment transport analysis is restricted [6]. In such cases mathematical modeling is very effective and reliable for studying the processes and pattern of sediment transport.

\section{Importance of Assessing Sediment Movement Pattern}

The study on sediment movement can provide vital information for the direction of sediment transportation, its quantity and also the processes that governs this transportation. Sediment movement also plays an important role in determining areas of coastal erosion and accretion. The shape and orientation of the coastal landforms and the evolving coastline is primarily based on sediment transportation. Hence, studies of sediment transport in the nearshore coastal area are of utmost importance for coastal protection strategies, designing and maintaining port and harbors, fisheries, marine

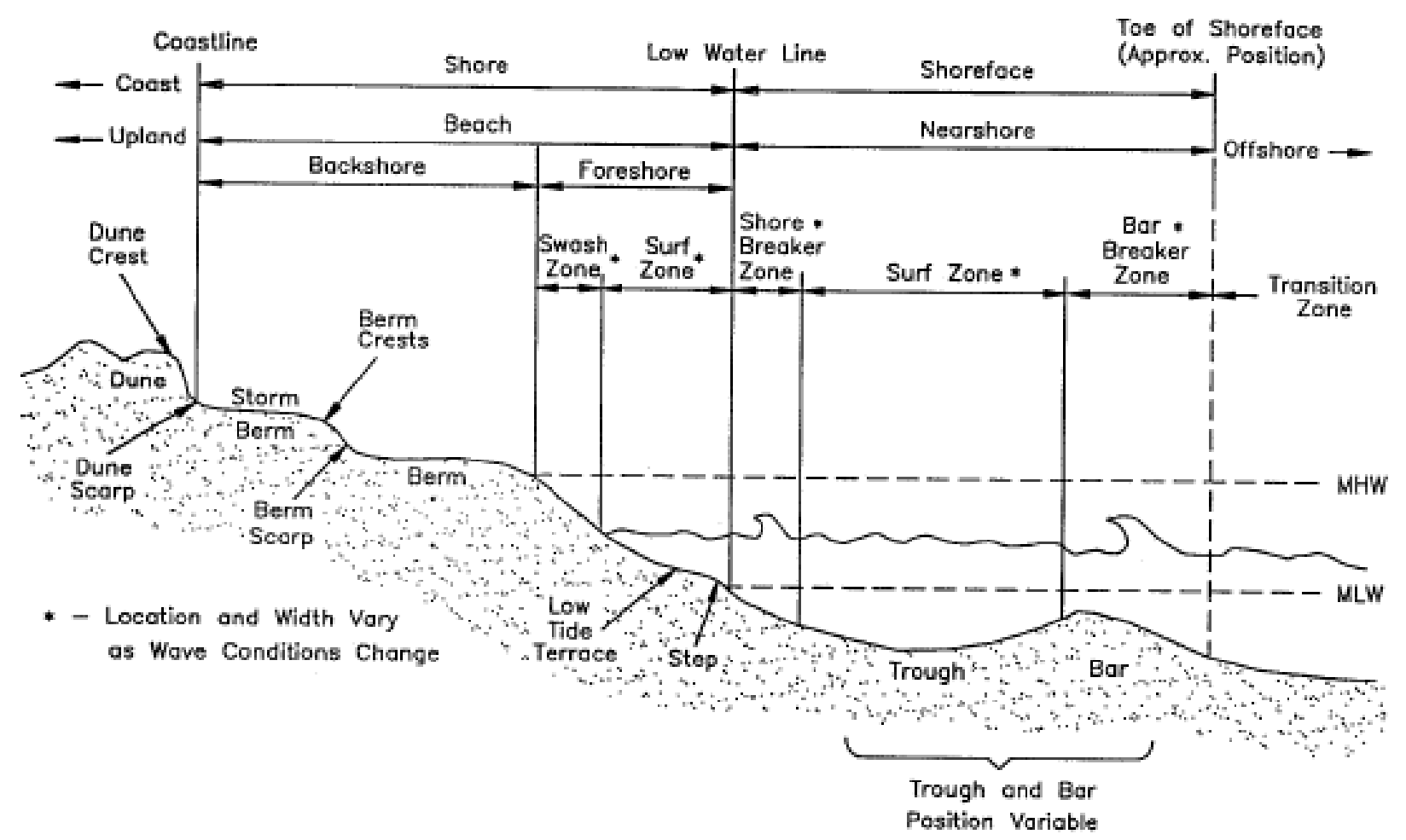

Fig. 1 Typical profile of a beach (Source: SPM, Volume I). 
recreation and land reclamation. In system with boundaries that are subject to deposition or scour, it is necessary to model the movement of the sediment particles with the flow to study different phenomena of the coast. These models are used to improve the understanding of different morphological processes also. Although sediment transport modeling is a complex topic and is subject to much uncertainty, mathematical modeling is comparatively effective in studying sediment transport including yield, distribution and management of sediment [7]. To develop and understand the physical processes responsible for shaping the ongoing evolution of the coast and to develop the management strategies to deal the impact of human activities on the coastal zone and as well as for adapting to the hazards associated with the people living on the coast, knowledge of the mechanism, processes and the pattern of sediment movement in the nearshore zone is the key component.

\section{Mathematical Model and Its Relation to Reality}

There are two types of model: mathematical model and physical model. Mathematical and numerical modeling is based on computing techniques as opposed to physical modeling which is based on traditional laboratory techniques and measurement. Mathematical modeling has become very popular in the past few decades, mainly due to the increasing availability of more powerful and affordable computing platforms. A mathematical model is a description of a system using mathematical concepts and language. It is a method of simulating real-life situations with mathematical equations to forecast their behavior. It is also an established, habitual, logical, or prescribed practice or systematic process of achieving certain ends with accuracy and efficiency, usually in an ordered sequence of fixed steps. A model may help to explain a system and to study the effects of different components, and to make predictions about it. Mathematical model makes it possible to avoid heavy expenses, which is required for direct study or trial and improvement method. Mathematical model also creates the opportunities to assess those tough phenomena relevantly shorter period of time, compare to other methodology like trial and improvement, direct study, experimental approach. Modeling gives a possibility to formulate hypotheses and to receive new knowledge about the object which is unavailable before. Lack of agreement between theoretical mathematical models and experimental measurements often leads to important advances as better theories are developed [8]. Mathematical modeling is very effective in studying sediment transport including yield, distribution and management of sediment. Generally for fluid flow, the mathematical model for sediment transport is usually based on conservation laws. A number of additional auxiliary equations are needed such as for the bed material sorting, bed resistance, sediment transport capacity etc. [9]. Reliable field data and in-depth understanding of mechanism of sediment transport are essential for verification and improvement of mathematical modeling.

\section{Different Studies on Mathematical Model to Assess Nearshore Sediment Movement}

Kim and Wang [9] developed a time-dependent 3-D nearshore morphological response numerical model which includes the slope effect, undertow current, wave-borne transport, and transition zone effect which are very important but often not estimated in other sediment transport models. The model is capable of predicting the growth and movement of main breakpoint bars and beach processes with reasonable reliability. An application of the model to different coastal structures including groins and breakwaters shows the model is capable of producing the general scouring, accretion and erosion features found in nature.

Simpson and Castelltort [10] presented a mathematical model coupling water flow and sediment transport dynamics that enables calculating the changing surface morphology through time and space. 
Here the sediment transport model is a non-capacity formulation whereby erosion and deposition are treated independently and influence the sediment flux by exchanging mass across the bottom boundary of the flow. The developed model can be used to investigate morphological changes induced by extreme events such as tsunami.

Splinter [3] developed 2D models to estimate nearshore bathymetry and sediment transport. The last project of his thesis explored the utilization of changes in bathymetry, $\Delta \mathrm{h} / \Delta \mathrm{t}$, to gain further understanding of the feedbacks between 2D sediment transport patterns, Qx and Qy, with respect to existing bathymetry in the nearshore.

A two-dimensional numerical model was developed for the simulation of sediment transport under oscillatory sheet flow conditions in the nearshore zone by Bakhtyar et al. [11]. An Eulerian two-phase flow model presented to understand the two-dimensional sediment transport in the sheet flow under non-breaking waves.

Chen et al. [12] developed a quasi-3D nearshore circulation and sediment transport model. A new version of nearshore circulation model, SHORECIRC, is developed by using a hybrid finite-difference finite-volume TVD-type scheme, and coupled with the wave model SWAN in the Nearshore Community Model System (NearCoM). Alongwith two sediment transport formulations included in the model package, the new model is named NearCoM-TVD.

A one-dimensional mathematical model presented by Larson and Hanson [13] that describes the cross-shore evolution of a long linear mound of noncohesive sediment placed in the nearshore. The model was developed for calculating the time-averaged net cross-shore transport rate and evolution of mounds placed where non-breaking waves prevail.

\section{Assessment on Suspended Sediment Movement along the Coast of Cox's Bazar}

\subsection{Study Area}

The study area is located along the Cox's bazar
Coastline of Bangladesh. It included the Inani beach, kolaboti beach, Laboni beach and the adjacent area of Moheshkhali channel. A mathematical model was set up for 5,272.2 square $\mathrm{km}$ area from Cox's Bazar beach and the adjacent nearshore water of Bay of Bengal. Among them about 375 square $\mathrm{km}$ area is land area and 4,897 square km area from Bay of Bengal.

\subsection{Methodology}

In this research a two dimensional hydrodynamic DIVAST (Depth Integrated Velocity and Solute Transport) model has been set up for the study area. An observation was made on the movement of suspended sediment for following condition:

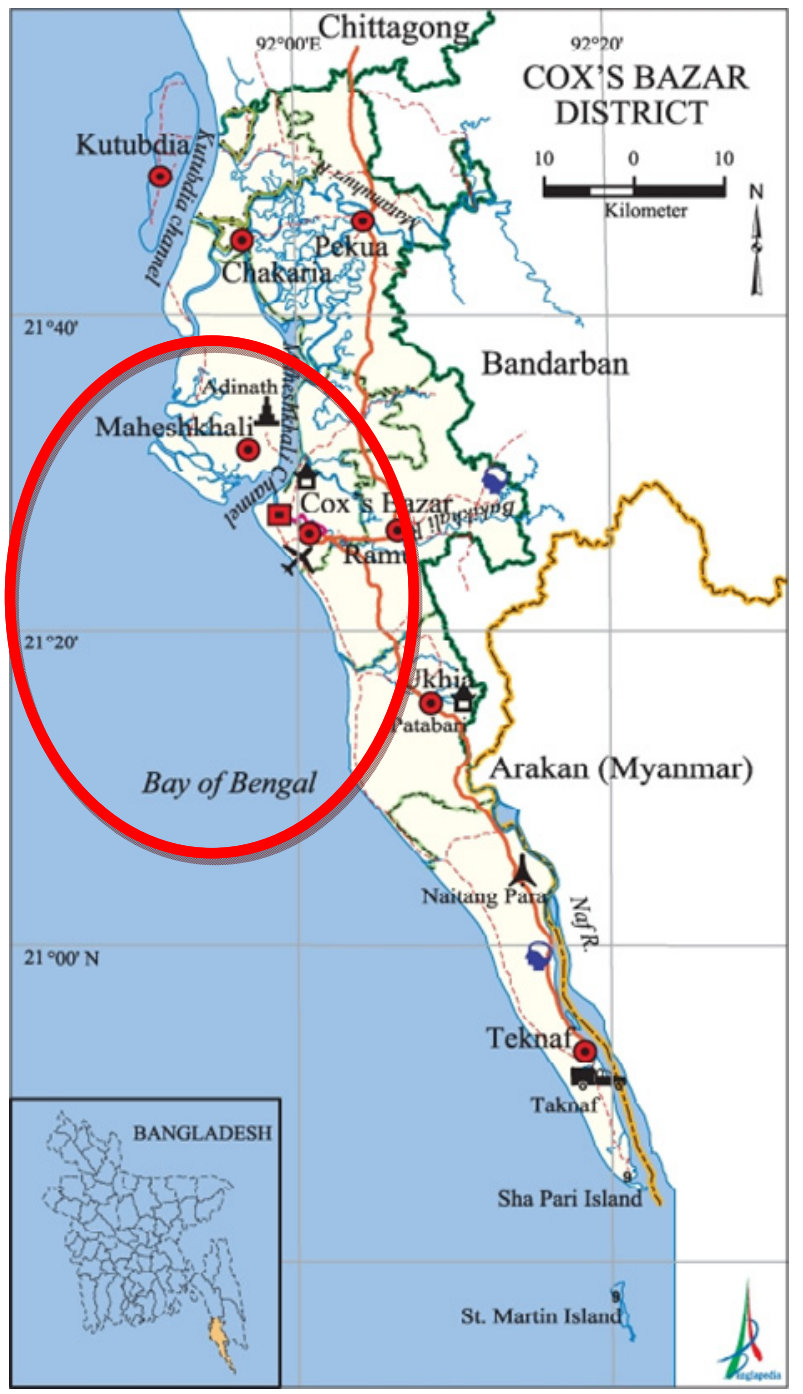

Fig. 2 Location of the Study area. 
Table 1 Summary of wave angle, height and period.

\begin{tabular}{|l|l|}
\hline Wave angle $\left(\theta^{\circ}\right)$ & $240^{\circ}$ \\
\hline Wave height $(\mathrm{m})$ & 1.59 \\
\hline Wave period $(\mathrm{sec})$ & 11.7 \\
\hline
\end{tabular}

DIVAST has a number of modules for different purposes and each module has different sets of equations. The hydrodynamic module of the DIVAST model is used for this research work to assess the suspended sediment movement pattern in the nearshore Coastal water of Cox's Bazar. To run the model the prerequisite was to keep the bathymetry data in the same pattern as per the command used in the FORTRAN based DIVAST model. The bathymetry data were organized successfully with the help of Google Earth and the orientation of the data was crosschecked by plotting contour map in Excel. There are three open boundaries in the study area, only one is closed. Among these three open boundaries one is totally open and the other two are partially open. By using Google Earth the adjacent point of the land and water were identified carefully to set up the boundary condition for the semi-open boundaries. The Maheshkhali channel was set up properly in this boundary condition which is inclusive in the study area. Different parameters such as tidal condition, water density, viscosity of water, D50, D90, breaking index, bed friction, Chezzy's C etc. were specified in the input file of the model for Cox's Bazar area. After the successful run of the model, the model output for suspended sediment after 30 minutes of starting a tidal cycle was plotted in surfer software (Fig. 3).

\subsection{Findings}

For incoming wave angle $240^{\circ}$, a significant amount of suspended sediment load approximately ranges from 4.5 to $28.5 \mathrm{Kg} / \mathrm{SM}$ is coming to the nearshore of Cox's Bazar coast from Bay of Bengal. The figure shows that in few points of the nearshore zone the sediment load is above $36.5 \mathrm{Kg} / \mathrm{SM}$. The sediment concentration is higher along the shore line but it tends to accumulate away from the Maheshkhali Channel.

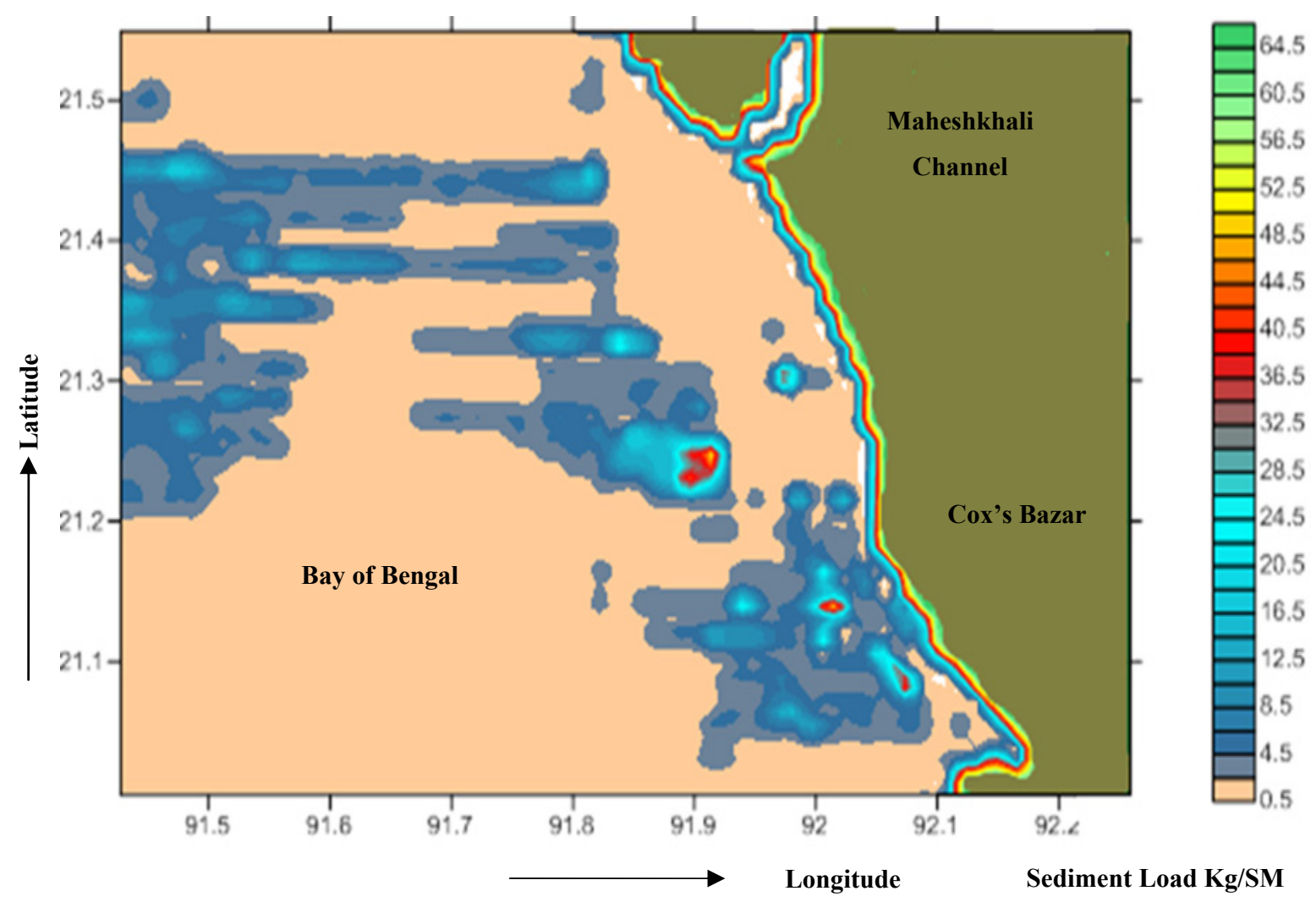

Fig. 3 Suspended sediment load for incoming wave angle $240^{\circ}$. 


\section{Conclusions}

Assessment of sediment movement pattern is an important factor and key component for different sector of coastal engineering. It can be a suitable practice to adopt a mathematical model for nearshore coastal water to assess the sedimentation pattern very easily and swiftly. Validity of forecast in sediment transport depends on both mathematical modeling technique and boundary conditions.

\section{References}

[1] Ashton, A., Murray, A. B., and Arnault, O. 2001. "Formation of Coastline Features by Large-Scale Instabilities Induced by High-Angle Waves." Nature 414 (6861): 296-300.

[2] Sarwar, G. 2005. "Impacts of Sea Level Rise on the Coastal Zone of Bangladesh." M.Sc. thesis of International Masters Programme in Environmental Science, Lund University, Sweden.

[3] Splinter, D. M. K. 2009. "Development of 2D Models to Estimate Nearshore Bathymetry and Sediment Transport." Doctor of Philosophy Dissertation, Oregon State University.

[4] Sierra, J. P., Azuz, I., Rivero, F., Sanchez, A., and Rodriguez, A. 1993. "Morphodynamic Modeling in the Nearshore Area." Laboratori d' Enginyeria maritime, Universitat Politenica de Catalunya, C/Gran capita s/n, 08034 Barcelona, Spain.

[5] Dean, R. G., and Dalrymple, R. A. 2002. Coastal Processes: with engineering Applications. Cambridge: Cambridge University Press.
[6] Oertel, G. F. 1972. "Patterns of Sediment Transport at Nearshore Zones Influenced by Wave and Tidal Currents: A Study Utilizing Fluorescent Tracers." Technical Report Series, Number 72-7, Georgia Marine Science Center, University System of Georgia.

[7] Kunte, P. D., Alagarsamy, R., and Hurthouse, A. S. 2013. "Sediment Fluxes and the Littoral Drift along Northeast Andhra Pradesh Coast, India: Estimation by Remote Sensing.” Environ. Monit. Assess 185 (6): 5177-92.

[8] Tan, Y. 2005. "Application of Mathematical Modeling to Sediment Research in the Three Gorges Project." US-China Workshop on Advanced Computational Modelling in Hydroscience \& Engineering, Oxford, Mississippi, USA.

[9] Kim, T., and Wang, H. 1996. "Numerical Modeling of Nearshore Morphological Changes under a Current-Wave Field." Nearshore Morphological Changes, chap. 296, 3830-45.

[10] Simpson, G., and Castelltort, S. 2006. "Coupled Model of Surface Water Flow, Sediment Transport and Morphological Evolution." Computers \& Geosciences 32: 1600-14.

[11] Bakhtyar, R., Yeganch, A., Barry, D. A., and Ghaheri, A. 2009. "Euler-Euler Coupled Two-Phase Flow Modeling of Sheet Flow Sediment Motion in the Nearshore." Journal of Coastal Research SI 56: 467-71.

[12] Chen, J., Shi, F., Hsu, T., and Kirby, J. T. 2014. "Near CoM-TVD-A Quasi-3D Nearshore Circulation and Sediment Transport Model." Coastal Engineering 91: 200-12.

[13] Larson, M., and Hanson, H. 2015. "Model of the Evolution of Mounds Placed in the Nearshore." Journal of Integrated Coastal Zone Management 15 (1): 21-33. 